\title{
Facilitation of Memory for Extinction of Drug-Induced Conditioned Reward: Role of Amygdala and Acetylcholine
}

\author{
Jason P. Schroeder ${ }^{1,3}$ and Mark G. Packard ${ }^{1,2,4}$ \\ ${ }^{1}$ Department of Psychology, Yale University, New Haven, Connecticut 06520, USA; ${ }^{2}$ Department of Psychology, Texas A \& M \\ University, College Station, Texas 77843, USA
}

\begin{abstract}
These experiments examined the effects of posttrial peripheral and intra-amygdala injections of the cholinergic muscarinic receptor agonist oxotremorine on memory consolidation underlying extinction of amphetamine conditioned place preference (CPP) behavior. Male Long-Evans rats were initially trained and tested for an amphetamine $(2 \mathrm{mg} / \mathrm{kg})$ CPP. Rats were subsequently given limited extinction training, followed by immediate posttrial peripheral or intrabasolateral amygdala injections of oxotremorine. A second CPP test was then administered, and the amount of time spent in the previously amphetamine-paired and saline-paired apparatus compartments was recorded. Peripheral $(0.07$ or $0.01 \mathrm{mg} / \mathrm{kg})$ or intra-amygdala $(10 \eta \mathrm{g} / 0.5 \mu \mathrm{L})$ postextinction trial injections of oxotremorine facilitated CPP extinction. Oxotremorine injections that were delayed $2 \mathrm{~h}$ posttrial training did not enhance CPP extinction, indicating a time-dependent effect of the drug on memory consolidation processes. The findings indicate that memory consolidation for extinction of approach behavior to environmental stimuli previously paired with drug reward can be facilitated by posttrial peripheral or intrabasolateral amygdala administration of a cholinergic agonist.
\end{abstract}

In the conditioned place preference (CPP) paradigm, the rewarding properties of a treatment are assessed by measuring approach behavior to environmental cues paired previously with the affective consequences of treatment administration. As numerous drugs with abuse potential in humans reliably induce a CPP in experimental animals, this task has been used extensively to investigate the neurobiological bases of drug reward (for reviews, see Carr et al. 1989; Tzschentke 1998). Following pairings of a drug treatment with a specific environmental context, the expression of a CPP is assessed on a treatment-free test day. Therefore, CPP behavior ultimately involves acquisition, consolidation, and retrieval of stimulus-reward memory for an association between environmental stimuli and the affective state produced by a treatment (White and Carr 1985; Hsu et al. 2002).

Extinction of memories mediating the control of approach behavior to environmental cues that have been associated with rewarding drug treatments represents a potentially significant therapeutic approach to human drug addiction. Importantly, several behavioral studies indicate that memory for CPPs is subject to extinction, as nonrewarded exposure to environmental contexts previously paired with rewarding drug treatments reduces subsequent CPP behavior (Bardo et al. 1986; Calcagnetti and Schecter 1993; Mueller and Stewart 2000; Parker and McDonald 2000; Itzhak and Martin 2001; Lu et al. 2002). Although extinction of CPP behavior has been demonstrated in several studies, the neurobiological basis of extinction in this task has not been extensively investigated. Several lines of evidence indicate that extinction involves new learning, rather than simple forgetting or erasure of original learning (see Bouton 1993; Rescorla 2001). Therefore, we have recently adapted the CPP task in

\footnotetext{
${ }^{3}$ Present address: Bowles Center for Alcohol Studies, University of North Carolina at Chapel Hill, Chapel Hill 27599, NC. ${ }^{4}$ Corresponding author.

E-MAIL mgp@psyc.tamu.edu; FAX (979) 845-4727.

Article and publication are at http://www.learnmem.org/cgi/doi/10.1101/ Im.78504.
}

order to examine whether administration of memory-enhancing agents would facilitate extinction of a drug-induced CPP. Specifically, our approach involves facilitating memory consolidation underlying extinction of CPP behavior by administering memory-enhancing drugs during the postextinction training time period. This methodology is based on extensive evidence indicating that posttrial administration of various drug treatments can facilitate memory consolidation for original learning in numerous behavioral tasks (for reviews, see McGaugh 1989, 2000). Moreover, administering treatments during the postextinction training period excludes influences on nonmnemonic factors that can potentially influence behavior when treatments are given prior to extinction training (i.e., sensory, motor, or motivational factors).

In our recent study, peripheral postextinction trial peripheral injections of glucose facilitated the extinction of an amphetamine CPP (Schroeder and Packard 2003). Peripheral administration of glucose increases acetylcholine release in various brain areas (Ragozzino et al. 1996), and evidence suggests that glucose and acetylcholine interact to modulate memory consolidation (Stone et al. 1988; Kopf and Baratti 1994; Blanchard and Duncan 1997; Kopf et al. 2001). In addition, peripheral posttraining administration of acetylcholine agonists can enhance memory consolidation in numerous behavioral tasks (see Baratti et al. 1979; Haroutunian et al. 1985; Gasbarri et al. 1993, 1997; Baratti and Kopf 1996). Taken together, these findings raise the possibility that acetylcholine agonists may also facilitate memory consolidation underlying the extinction of CPP behavior.

One brain area in which cholinergic drugs may potentially act to influence the extinction of CPP behavior is the amygdala. Excitotoxic lesions of the amygdala impair initial acquisition of various CPPs (Everitt et al. 1991; Hiroi and White 1991; Brown and Fibiger 1993; McDonald and White 1993), and posttraining intrabasolateral amygdala infusion of local anesthetics impairs memory consolidation for food (Schroeder and Packard 2000), and amphetamine (Hsu et al. 2002) CPPs. We have also recently observed that posttraining intrabasolateral amygdala infusion of 
the cholinergic muscarinic receptor antagonist scopolamine impairs memory consolidation underlying initial acquisition of CPPs for both food and amphetamine (Schroeder and Packard 2002). Other recent findings indicate a role for the basolateral amygdala in extinction of CPP behavior. Excitotoxic lesions of the basolateral amygdala made after initial training, but prior to extinction training, attenuate extinction of a cocaine CPP (Fuchs et al. 2002). In addition, similar to peripheral injections, postextinction trial infusion of glucose directly into the basolateral amygdala facilitates extinction of an amphetamine CPP (Schroeder and Packard 2003).

Evidence indicates that posttraining intra-amygdala infusions of the cholinergic muscarinic receptor agonist oxotremorine enhance memory consolidation during initial learning of several tasks (see Intrioni-Collison et al. 1996; Salinas et. al. 1997; Vazdarjanova and McGaugh 1999), and pretraining intraamygdala infusion of scopolamine disrupts cocaine-seeking behavior (See et al. 2003). Therefore, the present experiments examined the effects of postextinction training administration of oxotremorine on extinction of an amphetamine CPP. Experiment 1 investigated the effects of peripheral injections of oxotremorine, and Experiment 2 used intrabasolateral amygdala infusions of this cholinergic agonist.

\section{RESULTS}

\section{Experiment 1: Effects of Postextinction Trial Peripheral Infusions of Oxotremorine on Extinction of an Amphetamine CPP}

Figure 1 (top) shows the mean time spent in the amphetaminepaired and saline- paired compartments on the initial test session
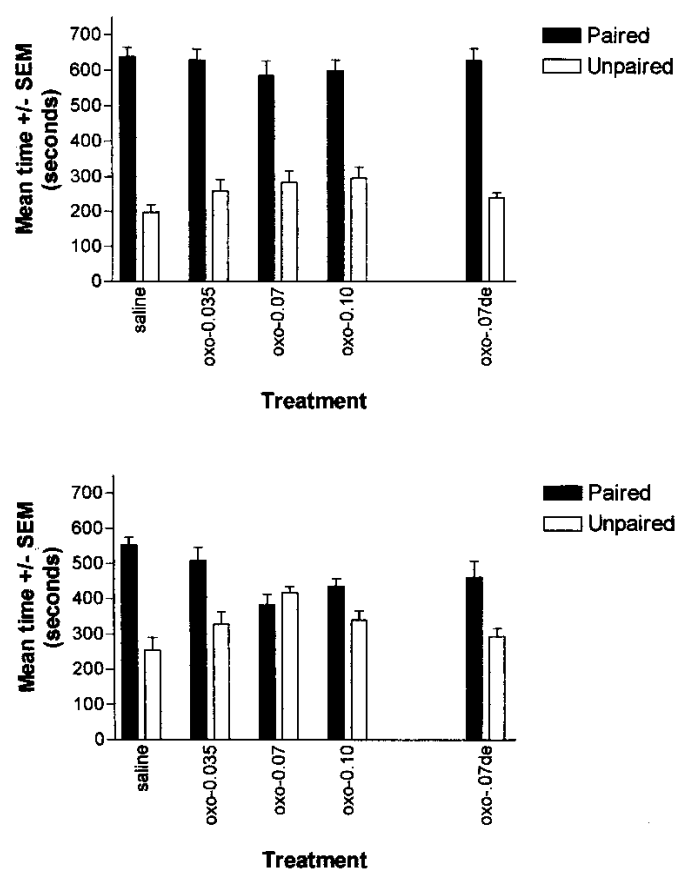

Figure 1 Effects of peripheral oxotremorine on amphetamine CPP extinction. (Top) Initial amphetamine CPP in rats to be subsequently exposed to extinction training. Mean time spent ( \pm SEM) in the previously paired (amphetamine) and unpaired (saline) compartments. All groups showed a significant CPP. (Bottom) Mean time spent ( \pm SEM) in the previously paired (amphetamine) and unpaired (saline) compartments following extinction training. Oxotremorine at doses of 0.07 and 0.10 $\mathrm{mg} / \mathrm{kg}$ significantly facilitated CPP extinction. Oxotremorine injections $(0.07 \mathrm{mg} / \mathrm{kg})$ delayed $2 \mathrm{~h}$ postextinction training were ineffective. (i.e., prior to extinction training). An ANOVA with postextinction trial treatment as a between-groups variable, and paired versus unpaired side as a repeated measure, revealed no significant interaction $\left(F_{(4,37)}=1.42, P=\mathrm{NS}\right)$ and a significant effect of side (paired versus unpaired side; $F_{(1,37)}=280.37, P<0.05$ ), demonstrating that all groups displayed an equivalent amphetamine CPP prior to extinction.

Figure 1 (bottom) shows the mean time spent in the amphetamine-paired and saline-paired compartments after extinction training for each of the groups. An ANOVA with postextinction trial treatment as a between-groups variable, and paired versus unpaired side as a repeated measure, revealed a significant interaction $\left(F_{(4,37)}=6.51, P<0.05\right)$. Planned comparisons revealed that subjects receiving postextinction training saline continued to demonstrate a significant CPP during the second test session and had therefore not extinguished $(t(7)=5.78, P<0.05)$. This finding in the control rats is consistent with our previous report that using the present training parameters, administration of two extinction trials is not sufficient to produce extinction of CPP behavior (Schroeder and Packard 2003). Similarly, rats receiving the lowest dose of oxotremorine $(0.035 \mathrm{mg} / \mathrm{kg})$ also continued to display a significant CPP during the second test session $(t(7)=3.194, P<0.05)$. In contrast, rats that received postextinction training injections of $0.07 \mathrm{mg} / \mathrm{kg}$ oxotremorine $(t(7)=-0.974$, $P=\mathrm{NS})$ and $0.10 \mathrm{mg} / \mathrm{kg}$ oxotremorine $(t(7)=2.21, P=\mathrm{NS})$ did not show a significant CPP during the second test session, indicating that administration of these doses of oxotremorine facilitate the extinction of an amphetamine CPP.

Rats administered oxotremorine $(0.07 \mathrm{mg} / \mathrm{kg})$ that was delayed $2 \mathrm{~h}$ postextinction continued to display an amphetamine CPP $(t(9)=4.162, P<0.05)$, indicating a time-dependent effect of oxotremorine on memory consolidation processes underlying CPP extinction. Importantly, this finding also indicates that the immediate postextinction trial injections of oxotremorine did not facilitate CPP extinction via a proactive effect on nonmnemonic factors (i.e., sensory, motor, or motivational factors).

\section{Experiment 2: Effects of Postextinction Trial Intrabasolateral Amygdala Infusions of Oxotremorine on Extinction of an Amphetamine CPP}

Figure 2 (top) shows the mean time spent in the amphetaminepaired and saline-paired compartments on the initial test session prior to group assignment. An ANOVA with postextinction trial treatment as a between-groups variable, and paired versus unpaired side as a repeated measure, revealed no significant interaction $\left(F_{(3,26)}=0.235, P=\mathrm{NS}\right)$ and a significant effect of side (paired versus unpaired side); $F_{(1,26)}=213.62, P<0.05$, demonstrating that all groups displayed an equivalent amphetamine CPP prior to extinction.

Figure 2 (bottom) shows the mean time spent in the amphetamine- and saline-paired compartments after extinction training for each of the groups. An ANOVA with postextinction trial treatment as a between-groups variable, and paired versus unpaired side as a repeated measure, revealed a significant interaction $\left(F_{(3,26)}=3.86, P<0.05\right)$. Planned comparisons revealed that subjects receiving postextinction training artificial cerebrospinal fluid (aCSF) continued to demonstrate a significant CPP during the second test session and had therefore not extinguished $(t(7)=3.55, P<0.05)$. Again, this finding in the control rats is consistent with our previous report that using the present training parameters, administration of two extinction trials is not sufficient to produce extinction of CPP behavior (Schroeder and Packard 2003). Similarly, rats receiving the high dose of oxotremorine (100 ng) also continued to display a significant CPP during the second test session $(t(7)=3.24, P<0.05)$. In contrast,

\section{Learning \& Memory}

www.learnmem.org 

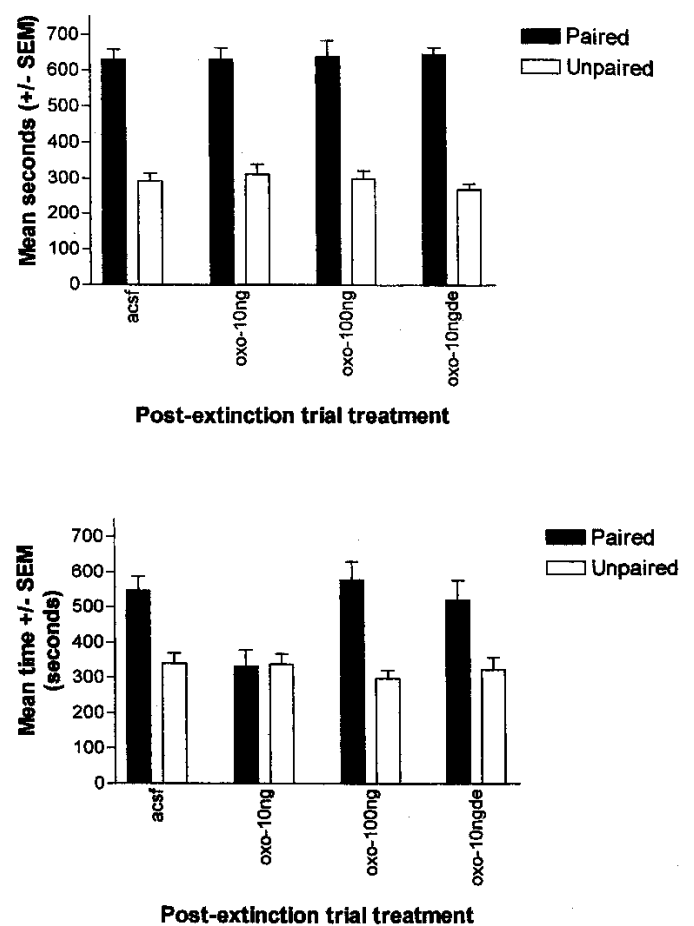

Figure 2 Effects of intra-amygdala oxotremorine on amphetamine CPP extinction. (Top) Initial amphetamine CPP in rats to be subsequently exposed to extinction training. Mean time spent $( \pm S E M)$ in the previously paired (amphetamine) and unpaired (saline) compartments. All groups showed a significant CPP. (Bottom) Mean time spent ( \pm SEM) in the previously paired (amphetamine) and unpaired (saline) compartments following extinction training. Oxotremorine at $10 \eta \mathrm{g} / 0.5 \mu \mathrm{L}$ significantly facilitated CPP extinction. Oxotremorine injections (10 ng/ $0.5 \mu \mathrm{L}$ ) delayed $2 \mathrm{~h}$ postextinction training were ineffective.

rats that received postextinction training injections of $10 \mathrm{ng}$ of oxotremorine did not show a significant CPP during the second test session $(t(7)=-0.15, P=N S)$, indicating that administration of this dose of oxotremorine facilitated the extinction of an amphetamine CPP.

Rats administered intra-amygdala oxotremorine (10 $\mathrm{ng})$ that was delayed $2 \mathrm{~h}$ postextinction continued to display an amphetamine CPP $(t(5)=4.153, P<0.05)$, indicating a time-dependent effect of oxotremorine on memory consolidation processes underlying CPP extinction. This finding also indicates that the immediate postextinction trial injections of oxotremorine did not facilitate CPP extinction via a proactive effect on nonmnemonic factors (i.e., sensory, motor, or motivational factors).

\section{DISCUSSION}

Postextinction training peripheral or intra-amygdala administration of the cholinergic muscarinic receptor agonist oxotremorine facilitated the extinction of an amphetamine CPP. To our knowledge, the findings are the first to demonstrate enhanced memory consolidation for CPP extinction training by a specific neurotransmitter agonist. Other recent findings using memory impairing treatments also suggest that the new learning underlying extinction for inhibitory avoidance training (Santini et al. 2001) and contextual fear conditioning (Vianna et al. 2001) also undergoes a consolidation process.

The present findings are consistent with those of previous studies that used pretraining peripheral injections of cholinergic agents to examine the role of acetylcholine in extinction (for review, see Mason 1983). For example, pre-extinction injections of the muscarinic receptor antagonist atropine attenuate extinc- tion of passive avoidance behavior (Buresova et al. 1964), whereas pre-extinction inhibition of acetylcholinesterase enhances extinction of operant (Glazer 1972) and conditioned avoidance behavior (Russell et al. 1964). Although cholinergic agents were administered prior to extinction in these earlier studies, the present findings raise the possibility that the enhancement of extinction rate that was observed may have been mediated by a facilitation of cholinergic function during the postextinction training time period.

We have previously observed that posttraining blockade of acetylcholine receptors within the basolateral amygdala by the cholinergic muscarinic receptor antagonist scopolamine impairs the acquisition of food and amphetamine CPPs (Schroeder and Packard 2002). Taken together with the present findings, this suggests a neurochemical similarity between processes mediating memory consolidation for CPP acquisition and extinction. This conclusion is consistent with recent evidence indicating that the neurochemical processes that mediate memory formation and extinction are often similar in other types of behavioral tasks (see Falls et al. 1992; Lee and Kim 1998; Tung et al. 2001; Vianna et al. 2001; but see also Berman and Dudai 2001). Specifically, the ability of posttrial intra-amygdala infusions of oxotremorine to facilitate extinction of CPP behavior are consistent with evidence that intra-amygdala infusion of this cholinergic agonist also enhances the initial acquisition of contextual fear conditioning (Vazdarjanova and McGaugh1999), inhibitory avoidance (Intrioni-Collison et al. 1996), and memory for reductions in reward magnitude (Salinas et al. 1997). Moreover, the findings support the general hypothesis (Pavlov 1927; Bouton 1993; Rescorla 2001) that extinction is an active process that involves the creation of new memories, rather than the forgetting and/or erasure of memories established during training. In view of the hypothesis that memories become labile during retrieval and undergo a "reconsolidation" process (see Nader et al. 2000; but see also Lattal and Abel 2004), one interpretation of the present findings may be that postextinction oxotremorine enhanced extinction by impairing memory for the original learning. However, this explanation seems unlikely given that at the doses used in the present study, posttraining oxotremorine enhances initial memory consolidation in many tasks (see Intrioni-Collison et al. 1996; Salinas et al. 1997; Vazdarjanova and McGaugh 1999).

In the present study, peripheral and intra-amygdala postextinction trial injection of oxotremorine enhanced memory consolidation for CPP extinction in a fashion similar to that previously observed with glucose (Schroeder and Packard 2003). Other evidence indicates that glucose and acetylcholine can interact during memory formation, raising the possibility that the memory-enhancing effects of postextinction trial glucose may ultimately involve a cholinergic mechanism. For example, the cholinergic muscarinic receptor antagonist atropine blocks the memory-enhancing effects of posttraining glucose (Kopf and Baratti 1994). In addition, coadministration of subeffective doses of glucose and the acetylcholine precursor choline act synergistically to enhance consolidation of inhibitory avoidance memory, and this effect is attenuated by administration of atropine (Kopf et al. 2001). One mechanism by which glucose may enhance acetylcholine function is by serving as a precursor to this neurotransmitter in conditions of high acetylcholine demand. Acetylcholine is synthesized by the reaction of choline and acetyl-Co-A, and glucose serves as the main source of acetylCo-A (Quastel 1978). Although high-affinity choline uptake is generally the rate-limiting step for acetylcholine synthesis (Simon et al. 1976), the availability of acetyl-CoA appears to be the rate-limiting step in certain conditions (Gibson and Blass 1976; Bielarczyk and Szutowicz 1989), including when cholinergic neurons are activated (Ragozinno et al. 1998). 
In addition to acetylcholine, the neurotransmitter glutamate has also been implicated in the acquisition of CPP behavior and in extinction processes underlying other forms of emotional memory (Bespalov et al. 1994; Cervo and Samainin 1995; Tzschentke and Schmidt 1995; Kim et al. 1996; Stevens et al. 1997; Toth and Parker 1999). For example, peripheral (Baker and Azorlosa 1996) and intra-amygdala (Falls et al. 1992; Lee and Kim 1998) administration of glutamatergic NMDA antagonists block the extinction of various forms of fear conditioning. Moreover, recent evidence indicates that pre-extinction administration of the NMDA receptor agonist D-cycloserine either through the system or into the amygdala facilitates the extinction of fear conditioning (Walker et al. 2002). Therefore, future research examining the role of intra-amygdala NMDA receptors in the extinction of stimulus-reward associations mediating CPP behavior is warranted.

The present experiments do not reveal the cellular mechanism(s) by which posttraining peripheral and intra-amygdala infusions of the acetylcholine agonist oxotremorine facilitate memory for CPP extinction. Muscarinic receptor activation increases the excitability of basolateral amygdala neurons (Washburn and Moises 1992; Womble and Moises 1992, 1993), which could conceivably enhance consolidation of memory traces directly within the amygdala. Consistent with this possibility, acetylcholine can modulate the induction of long-term potentiation (LTP), a putative cellular model of learning and memory that has been demonstrated in the amygdala (Chapman et al. 1990; Huang and Kandel 1998). Although to our knowledge the role of acetylcholine in amygdala LTP has not been investigated, this transmitter has been shown to play a role in LTP in other brain regions. For example, application of oxotremorine (Iga et al. 1996), or the AChE inhibitor (-)huperzine A (Ye et al. 2001), enhances, whereas scopolamine reduces hippocampal CA1 area LTP induction (Kobayashi et al. 1997; Ye et al. 2001). Acetylcholine also influences neocortical LTP in freely moving rats, as the cholinergic agonist pilocarpine enhances, whereas scopolamine attenuates LTP induction (Boyd et al. 2000).

Alternatively, the activity of amygdala output neurons may ultimately modulate memory consolidation processes underlying extinction of CPP behavior occurring in other brain regions. Extensive evidence indicates that the basolateral amygdala modulates memory consolidation occurring in other brain regions during initial acquisition of some types of learning tasks (e.g., hippocampus, caudate nucleus, and neocortex; Packard et al. 1995; Packard and Teather 1998; McGaugh et al. 2002). One brain area that receives a prominent glutamatergic input from the basolateral amygdala is the nucleus accumbens (see Wright et al. 1996; French and Totterdell 2003), and this structure has been extensively implicated in acquisition and expression of CPP behavior (for reviews, see Carr et al. 1989; Tzshentke 1998). Extinction exposure to a cocaine self-administration environment results in decreases in c-fos expression in the nucleus accumbens, and this reduction correlates with the strength of subsequent drug-seeking behavior (Neisewander et al. 2000). Other findings indicate interactions between the basolateral amygdala and nucleus accumbens in mediating the memory-enhancing effects of posttraining glucocorticoid administration (Roozendaal et al. 2001). The medial prefrontal cortex is an additional brain region that shares functional connectivity with the basolateral amygdala (see McDonald et al. 1996), and this structure has also been implicated in initial acquisition of cocaine CPP behavior (Tzschentke and Schmidt 1988; Isaac et al. 1989). Further research is necessary to examine whether extinction of CPP behavior ultimately involves the formation of memory traces directly within the amygdala or modulation of memory processes occurring in other brain areas.
Finally, the present findings may have implications for the treatment of human drug addiction. Exposure of addicts to formerly drug-related cues induces drug craving (Childress et al. 1986) and activates brain areas, including the amygdala (Childress et al. 1999), that may underlie associations formed between previously neutral cues and the affective consequences of addictive drugs. The ability of drug-paired cues to induce craving is presumably one of the mechanisms by which addiction endures. Our findings (present study; Schroeder and Packard 2003) indicating that posttraining administration of memory-enhancing agents can facilitate extinction of approach behavior to environmental stimuli associated with drug reward may therefore aid in the development of pharmacological therapies aimed at reducing drug-seeking behaviors in humans.

\section{MATERIALS AND METHODS}

\section{Subjects}

The subjects were 65 adult male Long-Evans rats (300 to $375 \mathrm{~g}$ ). They were individually housed in a temperature-controlled environment on a 12-h light/12-h dark cycle with the lights on from 7:00 a.m. to 7:00 p.m. and had ad libitum access to food and water prior to surgery.

\section{Surgery and Histology}

Prior to surgery, rats were anesthetized with a cocktail of $30 \mathrm{mg} /$ $\mathrm{kg}$ ketamine $\mathrm{HCl}$ and $2.5 \mathrm{mg} / \mathrm{kg}$ xylazine. Bilateral guide cannulae (23 gauge, $15 \mathrm{~mm}$ in length) were implanted overlying the basolateral amygdala by $1 \mathrm{~mm}$, using standard stereotaxic techniques. Jeweler's screws were anchored to the skull and attached to the cannula with dental acrylic. Stereotaxic coordinates for the basolateral amygdala placements were $\mathrm{AP}=-2.2 \mathrm{~mm}, \mathrm{ML}=$ \pm 4.7 from Bregma, and DV $=-7.0 \mathrm{~mm}$ from the skull surface. These coordinates were selected based on our previous research indicating that infusion of local anesthetics into this area blocks memory consolidation for food and amphetamine CPPs (Schroeder and Packard 2000; Hsu et al. 2002), and postextinction infusion of glucose at this brain site enhances extinction of an amphetamine CPP (Schroeder and Packard 2003).

After behavioral testing, rats were deeply anesthetized with a 1-mL injection of sodium pentobarbital $(50 \mathrm{mg} / \mathrm{mL})$ and perfused with a $10 \%$ formal-saline solution. Brains were removed and fixed in a $10 \%$ formal-saline solution before slicing. Frozen sections were cut at $20 \mu \mathrm{m}$ through the cannula tract area, and cresyl violet-stained sections were mounted and examined for verification of cannula placements by using the atlas of Paxinos and Watson (1997). The locations of injection sites in the basolateral amygdala are shown in Figure 3. Three rats were discarded due to misplacement of guide cannula. Histological analysis revealed that injection needle tip placements in the basolateral amygdala ranged from -2.30 to $-3.30 \mathrm{~mm}$ AP from Bregma.

\section{Apparatus}

The apparatus was identical to that used in our previous studies investigating the role of the basolateral amygdala in food and amphetamine CPP behavior (Schroeder and Packard 2000, 2003; Hsu et al. 2002). It was constructed of wood, with a Plexiglas front wall, and consisted of three compartments, two of which are identical in size $(45 \times 45 \times 30 \mathrm{~cm}$ high). One compartment was painted black with a black Plexiglas floor, and it had a piece of wire mesh on the ground, which was covered with $1 \mathrm{~mL}$ of a $1 \%$ acetic acid solution prior to training and test. The other compartment was painted white and had wood chips scattered over the floor. These two compartments were separated from each other by a wooden partition and were connected by a smaller back tunnel third compartment $(36 \times 18 \times 20 \mathrm{~cm}$ high), which had a metal floor and could be opened to allow entrance into each of the two larger compartments.

\section{Learning \& Memory}




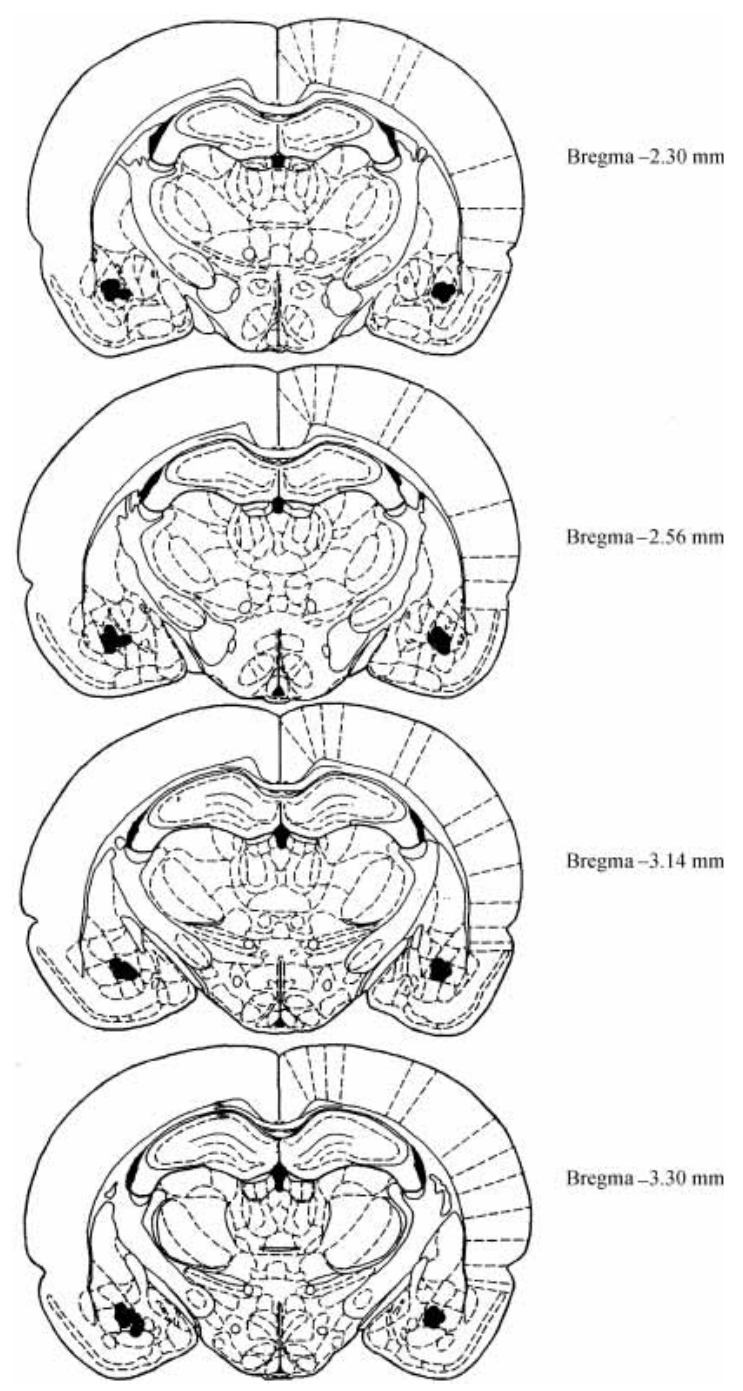

Figure 3 Needle injection sites in the basolateral amygdala (shown with overlap), and ranging from -2.30 to $-3.30 \mathrm{~mm}$ from Bregma. Illustrations were adapted from the rat brain atlas of Paxinos and Watson (1997).

\section{Drugs and Infusions}

D-Amphetamine and oxotremorine were obtained from SigmaAldrich. Amphetamine (Sigma-Aldrich; $2 \mathrm{mg} / \mathrm{kg}$ ) and oxotremorine (Sigma-Aldrich; 0.07, $0.01 \mathrm{mg} / \mathrm{kg}$ ) were dissolved in physiological $(0.9 \%)$ saline and injected into the intraperitoneal cavity. All peripheral drugs were injected at a volume of $1.0 \mathrm{~mL} / \mathrm{kg}$. Bilateral intrabasolateral amygdala infusions of oxotremorine (10 ng or $100 \mathrm{ng} / 0.5 \mu \mathrm{L}$ ) or aCSF vehicle were administered via an electronically controlled microsyringe pump by using $10-\mu \mathrm{L}$ Hamilton syringes connected to polyethylene tubing. The intracerebral infusions were administered over a 53 -sec period, and the injection needles (30 gauge, extending from the guide cannula by $1 \mathrm{~mm}$ ) were left in place an additional $60 \mathrm{sec}$ to allow for solution diffusion. The oxotremorine doses were selected based on their ability to enhance memory consolidation in various tasks (Baratti et al. 1979; Haroutunian et al. 1985; Gasbarri et al. 1993; Baratti and Kopf 1996; Intrioni-Collison et al. 1996; Salinas et al. 1997; Vazdarjanova and McGaugh 1999).

\section{Behavioral Procedures}

The behavioral procedures were identical to those of our previous research examining the effects of posttrial glucose on extinction of amphetamine CPP behavior (Schroeder and Packard 2003), and consisted of four general phases: CPP training, initial CPP testing, extinction training, and an additional CPP test. Training of the initial amphetamine CPP took place over 6 days. The first day consisted of habituation, during which rats were allowed access to all three compartments of the CPP apparatus for 10 min. The next 4 days consisted of two treatments and two nontreatment pairings, during which rats were confined to one of the two pairing compartments for 30 min immediately following administration of D-amphetamine or saline. In the present CPP apparatus, we have found that rats spend equal amounts of time in both of the large compartments during the habituation session (Schroeder and Packard 2003). Therefore, the present study used an unbiased CPP design in which half of the rats were injected with amphetamine prior to confinement in the black compartment and saline prior to confinement in the white compartment. The remaining half of the rats received amphetamine injections prior to exposure to the white compartment and saline injection prior to exposure to the black compartment. Half of the rats received their amphetamine injections on odd-numbered days, and the other half received amphetamine injections on even-numbered days. On day 6 , the rats were given a 20 -min drug-free test session and were allowed access to all three compartments of the apparatus. No treatments were administered prior to the test session, and the amount of time spent in the previous amphetamine-paired and saline-paired apparatus compartments was recorded as a measure of CPP behavior.

Twenty-four hours after the initial CPP test, rats were assigned to extinction groups that were matched with regard to the magnitude of their initial amphetamine CPP. Rats then received two extinction trials that were similar to original training (i.e., daily sessions in which they were alternatively placed in the formerly amphetamine- and saline-paired compartments for 30min). However, no treatments were administered prior to the extinction trials. In our previous research (Schroeder and Packard 2003) using the same training parameters as those of the present study, we observed that two extinction trials were not sufficient to produce extinction, whereas four or eight trials did produce extinction of CPP behavior. As the present study was designed to investigate whether a posttrial treatment could facilitate extinction, the two-extinction trial procedure was used.

Experiment 1 examined the effects of peripheral postextinction trial administration of oxotremorine on CPP extinction. Separate groups of rats received peripheral postextinction trial injections of saline $(\mathrm{n}=8)$, or oxotremorine $(0.035 \mathrm{mg} / \mathrm{kg}, \mathrm{n}=8$; $0.07 \mathrm{mg} / \mathrm{kg}, \mathrm{n}=8$; or $0.10 \mathrm{mg} / \mathrm{kg}, \mathrm{n}=8$ ). Experiment 2 examined the effects of intrabasolateral amygdala postextinction trial administration of oxotremorine on CPP extinction. Separate groups of rats received intrabasolateral infusions of aCSF $(n=8)$ or oxotremorine $(10 \mathrm{ng} / 0.5 \mu \mathrm{L}, \mathrm{n}=8$ or $100 \mathrm{ng} / 0.5 \mu \mathrm{L}, \mathrm{n}=8)$. or $2 \mathrm{~h}$ delayed oxotremorine $(10 \mathrm{ng} / 0.5 \mu \mathrm{L}, \mathrm{n}=6)$. Other groups of rats received initial amphetamine CPP training and testing, and peripheral or intrabasolateral amygdala oxotremorine injections that were delayed until $2 \mathrm{~h}$ after the extinction trials. These groups were tested in order to examine whether postextinction trial oxotremorine exerts a time-dependent effect on memory consolidation processes, and to control for potential proactive effects of oxotremorine on nonmnemonic factors (e.g., sensory, motoric, or motivational factors). The doses of oxotremorine used for the delayed injections $(0.07 \mathrm{mg} / \mathrm{kg}$ peripheral, $\mathrm{n}=6 ; 10$ $\mathrm{ng}$ intrabasolateral amygdala, $\mathrm{n}=6$ ) were selected following assessment of the effects of the immediate posttrial injections.

\section{ACKNOWLEDGMENTS}

Research was supported by National Institutes of Health Grant R29MH56973 (M.P).

\section{REFERENCES}

Baker, J.D. and Azorlosa, J.L. 1996. The NMDA antagonist MK-801

blocks the extinction of Pavlovian fear conditioning. Behav. Neurosci. 110: $618-620$.

Bardo, M.T., Neisewander, J.L., and Miller, J.S. 1986. Repeated testing 
attenuates conditioned place preference with cocaine. Psychopharmacology 89: 239-243.

Baratti, C.M. and Kopf, S.R. 1996. The post-training memory enhancement induced by physostigmine and oxotremorine in mice is not state-dependent. Neurobiol. Learn. Mem. 65: 121-124.

Baratti, C.M., Huygens, P., Mino, J., Merlo, A., and Gardella, J. 1979. Memory facilitation produced with posttrial injection of oxotremorine in mice. Psychopharmacology 64: 85-88.

Berman, D.E. and Dudai, Y. 2001. Memory extinction, learning anew, and learning the new: Dissociations in the molecular machinery of learning in the cortex. Science 291: 2417-2419.

Bespalov, A., Dumpis, M., Piotrovsky, L., and Zvartau, E. 1994. Excitatory amino acid receptor antagonist kynurenic acid attenuates rewarding potential of morphine. Euro. J. Pharmacol. 264: 233-239.

Bielarczyk, H. and Szutowicz, A. 1989. Evidence for the regulatory function of synaptoplasmic acetyl-CoA in acetylcholine synthesis in nerve endings. Biochem. I. 262: 377-380.

Blanchard, J.G. and Duncan, P.M. 1997. Effect of combinations of insulin, glucose, and scopolamine on radial arm maze performance. Pharmacol. Biochem. Behav. 58: 209-214.

Bouton, M.E. 1993. Context, time, and memory retrieval in the interference paradigms of Pavolovian learning. Psychol. Bull. 114: 80-99.

Boyd, T.E., Trepel, C., and Racine, R.J. 2000. Cholinergic modulation of neocortical long-term potentiation in the awake, freely moving rat. Brain Res. 881: 28-36.

Brown, E. and Fibiger, H. 1993. Differential effects of excitotoxic lesions of the amygdala on cocaine-induced locomotion and conditioned place preference. Psychopharmacology 113: 123-130.

Buresova, O.J., Bures, Z., Bohdanecky, Z., and Weiss, T. 1964. Effect of atropine on learning, extinction, retention, and retrieval in rats. Psychopharmacology 5: 255-293.

Carr, G.D., Fibiger, H.C., and Philips, A.G. 1989. Conditioned place preference as a measure of drug reward. In Oxford reviews in psyhopharmacology: Neuropharmacological basis of reward, Vol. 1, (eds. J.M. Leibman and S.J. Cooper), pp. 265-319. Oxford University Press, New York.

Cervo, L. and Samanin, R. 1995. Effects of dopaminergic and glutamatergic antagonists on the acquisition and expression of cocaine conditioned place preference. Brain Res. 673: 242-250.

Chapman, P.F., Kairiss, E.W., Keenan, C.L., and Brown, T.H. 1990. Long-term synaptic potentiation in the amygdala. Synapse 6: $271-278$

Childress, A.R., McLellan, A.T., Ehrman, R.N. and O’Brien, C.P. 1986. Extinction of conditioned responses in abstinent cocaine or opioid users. NIDA Res. Monogr. 76: 189.

Childress, A.R., Mozley, P.D., McElgin, W., Fitzgerald, J., Reivich, M., and O'Brien, C.P. 1999. Limbic activation during cue-induced cocaine craving. Am. J. Psychiatry 156: 11-18.

Calcagnetti, D.J. and Schechter, M.D. 1993. Extinction of cocaine-induced place approach in rats: A validation of the "biased" conditioning procedure. Brain Res. Bull. 30: 695-700.

Everitt, B.J., Morris, K.A., O'Brein, A., and Robbins, T.W. 1991. The basolateral amygdala-ventral striatal system and conditioned place preference: Further evidence of limbic-striatal interactions underlying reward-related processes. J. Neurosci. 42:1324-1334.

Falls, W.A., Miserendino, M.J.D., and Davis, M. 1992. Extinction of fear-potentiated startle: Blockade by infusion of an NMDA antagonist into the amydala. J. Neurosci. 12: 854-863.

French, S.J. and Totterdell, S. 2003. Individual nucleus accumbens-projection neurons receive both basolateral amygdala and ventral subicular afferents in rats. Neuroscience 119: 19-31.

Fuchs, R.A., Weber, S.M., Rice, H.J., and Neiswander, J.L. 2002. Effects of excitotoxic lesions of the basolateral amygdala on cocaine-seeking behavior and cocaine conditioned place preference in rats. Brain Res. 929: $15-25$.

Gasbarri, A., Intrioini-Collison, I.B., Packard, M.G., Pacitti, C., and McGaugh, J.L. 1993. Interaction of cholinergic-dopaminergic systems in the regulation of memory storage in aversively motivated learning tasks. Brain Res. 627: 72-78.

Gasbarri, A., Sulli, A., Pacitti, C., Puglisi-Allegras, S., Cabib, S., Castellano, C., Intrioni-Collison, I., and McGaugh, J.L. 1997. Strain-dependent effects of $\mathrm{D}_{2}$ dopaminergic and muscarinic-cholinergic agonists and antagonists on memory consolidation processes in mice. Behav. Brain Res. 86: 97-104.

Gibson, G.E. and Blass, J.P. 1976. Impaired synthesis of acetylcholine in brain accompanying mild hypoxia and hypoglycemia. J. Neurochem. 27: $37-42$.

Glazer, H.I. 1972. Physostigmine and resistance to extinction. Psychopharmacology (Berlin) 26: 387-394.

Haroutunian, V., Barnes, E., and Davis, K.L. 1985. Cholinergic modulation of memory in rats. Psychopharmacology 87: 266-271.
Hiroi, N. and White, N.M. 1991. The lateral nucleus of the amygdala mediates expression of amphetamine-produced place preference. $J$. Neurosci. 11: 2107-2116.

Hsu, E.H., Schroeder, J.P., and Packard, M.G. 2002. The amygdala mediates memory consolidation for an amphetamine conditioned place preference. Behav. Brain Res. 129: 93-100.

Huang, Y.Y. and Kandel, E.R. 1998. Postsynaptic induction and PKA-dependent expression of LTP in the lateral amygdala. Neuron 21: $169-178$.

Iga, Y., Arisawa, H., Ise, M., Yasuda, H., and Takeshita, Y. 1996 Modulation of rhythmical slow activity, long-term potentiation and memory by muscarinic receptor agonists. Eur. J. Pharmacol. 308: $13-19$.

Introini-Collison, I.B., Dalmaz, C., and McGaugh, J.L. 1996. Amygdala B-noradrenergic influences on memory storage involve cholinergic activation. Neurobiol. Learn. Mem. 65: 57-64.

Isaac, W.L., Nonnman, A.J., Neisewander, J.L., Landers, T., and Bardo, M.T. 1989. Prefrontal cortex lesions differentially disrupt cocaine-reinforced responding, but not conditioned taste aversion. Behav. Neurosci. 103: 345-355.

Itzhak, Y. and Martin, J.L. 2001. Cocaine-induced conditioned place preference in mice: Induction, extinction, and reinstatement by related psychostimulants. Neuropsychopharmacology 26:130-134.

Kim, H.S., Jang, C.G., and Park, W.K. 1996. Inhibition by MK-801 of morphine-induced conditioned place preference and postsynaptic dopamine receptor supersensitivity in mice. Pharmacol. Biochem. Behav. 55: 11-17.

Kobayashi, M., Ohno, M., Shibata, S., Yamamoto, T., and Watanabe, S. 1997. Concurrent blockade of $\beta$-adrenergic and muscarinic receptors suppresses synergistically long-term potentiation of population spikes in the rat hippocampal CA1 region. Brain Res. 777: 242-246.

Kopf, S.R. and Baratti, C.M. 1994. Memory-improving actions of glucose: Involvement of a central cholinergic mechanism. Behav. Neural Biol. 62: 237-243.

Kopf, S.R., Buchholzer, M.L., Hilgert, M., Loffelholz, K., and Klein, J. 2001. Glucose plus choline improve passive avoidance behavior and increase hippocampal acetylcholine release in mice. Neuroscience 103: $365-371$

Lattal, K.M. and Abel, T. 2004. Behavioral impairments caused by injections of the protein synthesis inhibitor anisomycin after contextual retrieval reverse with time. Proc. Natl. Acad. Sci. 101: 4667-4672.

Lee, H. and Kim, J.J. 1998. Amygdalar NMDA receptors are critical for new fear learning in previously fear-conditioned rats. J. Neurosci. 18: $8444-8454$.

Lu, L., Zhang, B., Liu, Z., and Zhang, Z. 2002. Reactivation of cocaine conditioned place preference induced by stress is reversed by cholecystokinin-B receptor antagonists in rats. Brain Res. 954: $132-140$.

Mason, S.T. 1983. The neurochemistry and pharmacology of extinction behavior. Neurosci. Biobehav. Rev. 7: 325-347.

McDonald, R.J. and White, N.M. 1993. A triple dissociation of memory systems: Hippocampus, amygdala, and dorsal striatum. Behav. Neurosci. 107: 3-22.

McDonald, A.J., Mascagni, F., and Guo, L. 1996. Projections of the medial and lateral prefrontal cortices to the amygdala: A Phaseolus vulgaris leucoagglutinin study in the rat. Neuroscience 71: 55-75.

McGaugh, J.L. 1989. Dissociating learning and performance: Drug and hormone enhancement of memory storage. Brain Res. Bull. 23: $339-345$.

. 2000. Memory: A century of consolidation. Science 287: 248-251.

McGaugh, J.L., McIntyre, C.K., and Power, A.E. 2002. Amygdala modulation of memory consolidation: Interaction with other brain systems. Neurobiol. Learn. Mem. 78: 539-552.

Mueller, D. and Stewart, J. 2000. Cocaine-induced conditioned place preference: Reinstatement by priming injections of cocaine after extinction. Behav. Brain Res. 115: 39-47.

Nader, K., Schafe, G.E., and Ledoux, J.E. 2000. Fear memories require protein synthesis in the amygdala for reconsolidation after retrieval. Nature 406: 722-726.

Neisewander, J.L., Baker, D.A., Fuchs, R.A., Tran-Nguyen, L.T., Palmer, A., and Marshall, J.F. 2000. Fos protein expression and cocaine-seeking behavior in rats after exposure to a cocaine self-administration environment. J. Neurosci. 20: 798-805.

Packard, M.G. and Teather, L.A. 1998. Amygdala modulation of multiple memory systems: Hippocampus and caudate-putamen. Neurobiol. Learn. Mem. 69: 163-203.

Packard, M.G., Cahill, L., Williams, C.L., and McGaugh, J.L. 1995. The anatomy of a memory modulation system: From periphery to brain. In Neurobehavioral plasticity: Learning, development, and response to brain insults (eds. N.E. Spear et al.), pp.149-183. Erlbaum, Hillsdale, NJ. 
Parker, L.A. and McDonald, R.V. 2000. Reinstatement of both a conditioned place preference and a conditioned place aversion with drug primes. Pharmacol. Biochem. Behav. 66: 559-561.

Pavlov, I.P. 1927. Conditioned reflexes: An investigation of physiological activity of the cerebral cortex. Oxford University Press, London.

Paxinos, G. and Watson, C. 1997. The rat brain in stereotaxic coordinates, 3rd ed. Academic Press, San Diego, CA.

Quastel, J.H. 1978. Source of the acetyl group in acetylcholine. In Cholinergic mechanisms and psychopharmacology (ed. D.J. Jenden), pp. 411-430. Plenum, New York.

Ragozzino, M.E., Unick, K.E., and Gold, P.E. 1996. Hippocampal acetylcholine release during memory testing in rats: Augmentation by glucose. Proc. Natl. Acad. Sci. 93: 4693-4698.

Ragozzino, M.E., Pal, S.N., Unick, K., Stefani, M.R., and Gold, P.E. 1998. Modulation of hippocampal acetylcholine release and spontaneous alternation scores by intrahippocampal glucose injections. $J$. Neurosci. 18: 1595-1601.

Rescorla, R.A. 2001. Experimental extinction. In Handbook of contemporary learning theories (eds. R.R. Mowrer and S. Klein), pp. 119-154. Erlbaum, Mahwah, NJ.

Roozendall, B., de Quervain, D.J., Ferry, B., Setlow, B., and McGaugh, J.L. 2001. Basolateral amygdala-nucleus accumbens interactions in mediating gluccocorticoid enhancement of memory consolidation. $J$. Neurosci. 21: 2518-2525.

Russell, R.W., Watson, R.H.J., and Frankenhauser, M. 1964. Effects of chronic reductions in brain cholinesterase activity on acquisition and extinction of a conditioned avoidance response. Scand. J. Psychol. 2: 21-29.

Salinas, J., Introini-Collison, I.B., Dalmaz, C., and McGaugh, J.L. 1997. Posttraining intra-amygdala infusion of oxotremorine and propranolol modulate storage for memory for reduction in reward magnitude. Neurobiol. Learn. Mem. 68: 51-59.

Santini, E., Muller, R.U., and Quirk, G.J. 2001. Consolidation of extinction learning involves transfer from NMDA-independent to NMDA-dependent memory. J. Neurosci. 21: 9009-9017.

Schroeder, J.P. and Packard, M.G. 2000. Differential effects of intra-amygdala lidocaine infusion on memory consolidation and expression of a food conditioned place preference. Psychobiology 28: $486-491$.

. 2002. Post-training intra-basolateral amygdala scopolamine impairs food and amphetamine conditioned place preferences. Behav. Neurosci. 116: 922-927.

. 2003. Systemic or intra-amygdala injections of glucose facilitate memory consolidation for extinction of drug-induced conditioned reward. Eur. J. Neurosci. 17: 1482-1488.

See, R.E., McGlaughlin, J., and Fuchs, R.A. 2003. Muscarinic receptor antagonism in the basolateral amygdala blocks acquisition of cocaine-stimulus association in a model of relapse to cocaine-seeking behavior in rats. Neuroscience 117: 477-483.

Simon, J.R., Atweh, S., and Kuhar, M.J. 1976. Sodium-dependent high affinity choline uptake: A regulatory step in the synthesis of acetylcholine. J. Neurochem. 26: 909-922.

Stevens, L., Shapiro, M., and White, N.M. 1997. Effects of NMDA receptor blockade on behaviors differentially affected by fimbria/fornix and amygdala lesions. Psychobiology 25: 109-117.

Stone, W.S., Croul, C.E., and Gold, P.E. 1988. Attenuation of scopolamine-induced amnesia in mice. Psychopharmacology 96: $417-420$.

Toth, J. and Parker, L.A. 1999. MK-801 interferes with the acquisition of amphetamine- and lithium-induced place conditioning. Anim. Learn. Behav. 27: 481-489.

Tung, L.K., Walker, D.L., and Davis, M. 2001. Mitogen-activated protein kinase cascade in the basolateral nucleus of amygdala is involved in extinction of fear-potentiated startle. J. Neurosci. 21: 1-5.

Tzschentke, T.M. 1998. Measuring reward with the conditioned place preference paradigm: A comprehensive review of drug effects, recent progress and new issues. Prog. Neurobiol. 56: 613-672.

Tzschentke, T.M. and Schmidt, W.J. 1988. Effects of discrete quinolinic acid lesions of the rat infralimbic medial prefrontal cortex on drug induced conditioned place preference. Behav. Pharmacol. 9: S87.

. 1995. $N$-Methyl-D-aspartic acid-receptor antagonists block morphine-induced conditioned place preference in rats. Neurosci. Lett. 193: $37-40$.

Vazdarjanova, A. and McGaugh, J.L. 1999. Basolateral amygdala is involved in modulating consolidation of memory for classical fear conditioning. J. Neurosci. 19: 6615-6622.

Vianna, M.R.M., Szapiro, G., McGaugh, J.L., Medina, J.H., and Izquierdo, I. 2001. Retrieval of memory for fear-motivated training initiates extinction requiring protein synthesis in the rat hippocampus. Proc. Natl. Acad. Sci. 98: 12251-12254.

Walker, D.L., Ressler, K.J., Lu, K.T., and Davis, M. 2002. Facilitation of conditioned fear extinction by systemic administration of intra-amygdala infusions of D-cycloserine as assessed with fear-potentiated startle in rats. J. Neurosci. 22: 2343-2351.

Washburn, M.S. and Moises, H.C. 1992. Muscarinic responses of rat basolateral amygdaloid neurons in vitro. J. Physiol. 449: 121-154.

White, N.M. and Carr, G.D. 1985. The conditioned place preference is affected by two independent reinforcement processes. Pharmacol. Biochem. Behav. 23: 37-42.

Womble, M.D. and Moises, H.C. 1992. Muscarinic inhibition of M-current and a potassium leak conductance in neurones of the rat basolateral amygdala. J. Physiol. 457: 93-114.

. 1993. Muscarinic modulation of conductances underlying the hyperpolarization in neurons of the rat basolateral amygdala. Brain Res. 621: 87-96.

Wright, C.I., Beijer, A.V., and Groenewegan, H.J. 1996. Basal amygdaloid complex afferents to the rat nucleus accumbens are compartmentally organized. J. Neurosci. 16: 1877-1893.

Ye, L., Qi, J., and Qiao, J. 2001. Long-term potentiation in hippocampus of rats is enhanced by endogenous acetylcholine in a way that is independent of $N$-methyl-D-aspartate receptors. Neurosci. Lett. 300: $145-148$.

Received April 2, 2004; accepted in revised form July 14, 2004. 


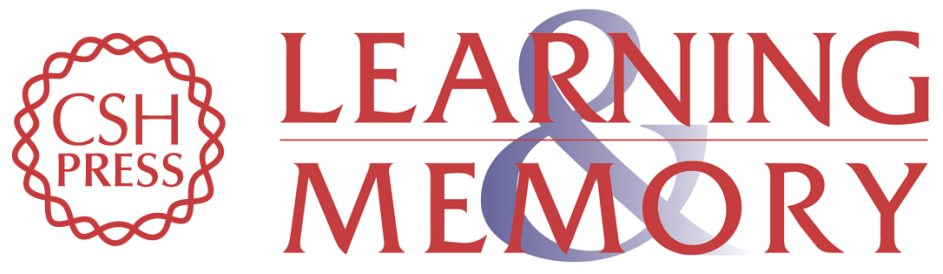

\section{Facilitation of Memory for Extinction of Drug-Induced Conditioned Reward: Role of Amygdala and Acetylcholine}

Jason P. Schroeder and Mark G. Packard

Learn. Mem. 2004, 11:

Access the most recent version at doi:10.1101/lm.78504

References This article cites 78 articles, 16 of which can be accessed free at:

http://learnmem.cshlp.org/content/11/5/641.full.html\#ref-list-1

License

Email Alerting Receive free email alerts when new articles cite this article - sign up in the box at the Service top right corner of the article or click here. 